ECCOMAS

Proceedia
COMPDYN 2021

$8^{\text {th }}$ ECCOMAS Thematic Conference on Computational Methods in Structural Dynamics and Earthquake Engineering

M. Papadrakakis, M. Fragiadakis (eds.)

\title{
PARAMETRIC STUDY OF LATTICE TOWERS ON THE INFLUENCE OF WIND ACTION FOR DIFFERENT TYPOLOGIES OF BRACING
}

\author{
Carneiro-Barros Rui ${ }^{1}$, and Barros R.G. Luís ${ }^{2}$ \\ ${ }^{1}$ CONSTRUCT, Faculdade de Engenharia, Universidade do Porto \\ FEUP, Porto, Portugal \\ rcb@fe.up.pt \\ ${ }^{2}$ BSSE, Lda. - Porto, Portugal \\ luis.guimaraes.barros@gmail.com
}

\begin{abstract}
The telecommunications sector is a fundamental pillar of today's society. The answer to the need for constant communication is based on a network of structures, that allows the uninterrupted functioning of the communication system. Among these structures of the communication infrastructure are the so-called telecommunications towers, which are fundamental elements for the functioning of the system. Therefore, given the importance and actual demand for these structures, there is a great need for a deep knowledge of their behaviour, to find more economically viable and safer solutions. Since the wind action is in fact the most significant and conditioning for the design of this type of structures, this work focusses on the study of different bracing schemes, which were divided into three groups differing by specific parameters or even locations. Starting from a base or initial model of a lattice tower designed according to Eurocodes (EC1 and EC3), five conceptual tower models were redesigned with different lay-out schemes, but without changing the territorial location and their height and width. These models were analysed and compared to understand how different bracing schemes can affected the wind action determination and what are their consequences on the behaviour of the structures and their design.
\end{abstract}

Keywords: Lattice towers, wind loading action, EN 1991-1-4, EN 1993-3-1, parametric study on bracing. 


\section{INTRODUCTION}

The development of today's society is also strongly linked to the ease and speed of communication and information sharing, and so it is not difficult to understand the importance of telecommunications towers, commonly present in the urban landscape and elsewhere. These structures, normally of great height, have as main objective the placement of transmission equipment on its top that allows the adequate transmission of signals. With an increasing use of mobile phones and the offer of services such as channel television, there is a greater need for the implantation of these structures to guarantee a good quality of all the services provided [1]. But despite the great importance of telecommunications towers to society, these structures exhibit statistically a higher number of failures when compared with many other structures [2]. Thus, it is essential to understand the behaviour of these structures, so that it is possible to design them as economically viable as possible, but still complying with safety criteria.

This work focusses on the study of different bracing schemes, which can be divided into three groups differing by specific parameters or even locations; a change or modification done to a specific tower parameter causes re-sizing of structural members to satisfy the structural design conditions for the tower wind actions at the implantation site [3]. Starting from a base model of a lattice tower designed according to Eurocodes (EC1 and EC3), conceptual tower models were redesigned with different lay-out of bracing schemes, but without changing the territorial location and the tower height and width. These models were analysed and compared to understand how different bracing schemes can affected the wind action determination and what are their consequences on the behaviour of the structures and their design.

\section{DESCRIPTION OF CONCEPTUAL TOWER MODELS}

\subsection{Initial Tower Model for Reference Comparison}

The initial model of the tower, predesigned by the industrial partner Metalogalva - Irmãos Silva SA according to this metalo-mechanical company experience on lattice towers and its industrial production characteristics (including delivery and assemblage at specific locations), consists of a self-supporting lattice tower with a triangular section 100 meters high and 15 meters wide at the base.

The tower can be divided into two distinct tower segments: the first or lower segment, from the base to about two thirds of the height, up to 72.5 meters, uses the K-typology scheme as the main bracing system in elevation along the height; the second or upper segment, in the last 27.5 meters, uses lattice diagonal bracing because this tower segment width is much smaller.

The diaphragms, which constitute horizontal stiffening zones or horizontal bracing systems, are spaced 6 meters apart up to 72.5 meters in height of the first tower segment; in the last 27.5 meters, the diaphragms of the second tower segment are spaced 3 meters apart.

Table 1 indicates the characteristics of the initial tower model; and Figure 1 shows the general 3D layout. 
Table 1 : Characteristics of the initial tower model

\begin{tabular}{cc} 
Total height & $100 \mathrm{~m}$ \\
\hline Top width & $3 \mathrm{~m}$ \\
\hline Base width & $15 \mathrm{~m}$ \\
\hline Number of sub-segments $(12+10)$ & 22 \\
\hline Type of profile used & Circular \\
\hline Steel class & $\mathrm{S} \mathrm{355}$ \\
\hline Ultimate stress $\left(f_{u}\right)$ & $510 \mathrm{MPa}$ \\
\hline Yield stress $\left(f_{y}\right)$ & $355 \mathrm{MPa}$ \\
\hline Elasticity modulus $(E)$ & $210000 \mathrm{MPa}$ \\
\hline Distortion modulus $(G)$ & $81000 \mathrm{MPa}$ \\
\hline Poisson coefficient $(v)$ & 0.3 \\
\hline Coefficient of thermal expansion $(\alpha)$ & $12 \times 10^{-6} /{ }^{\circ} \mathrm{C}$
\end{tabular}

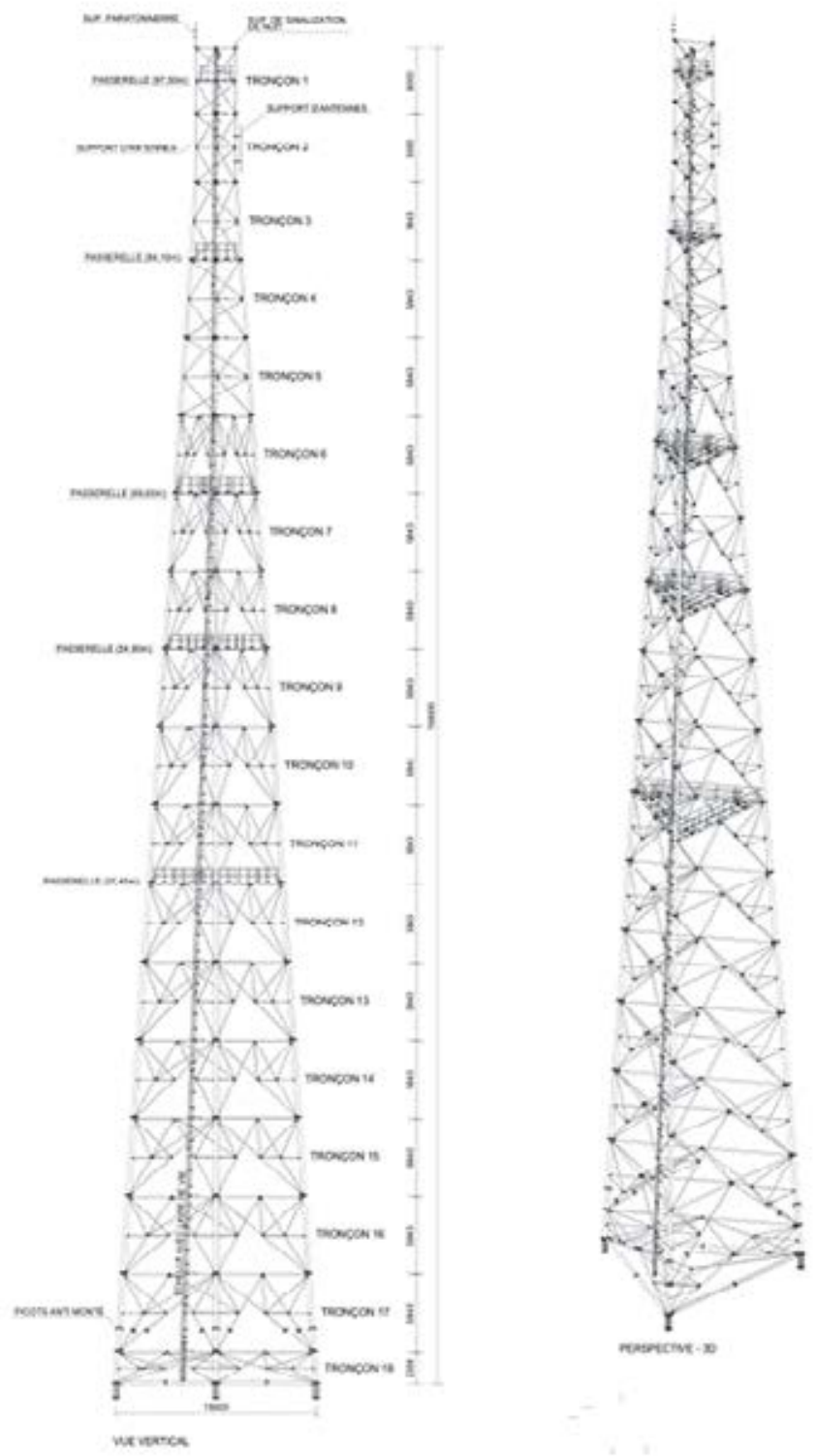

Figure 1 : Initial tower model. 


\subsection{Tower Model A}

This tower model A (shown in Figure 2) is very similar to the initial tower model, the only change occurring in the upper tower segment with a truss system where a new circular profile member was added in the opposite direction to the existing one; therefore, making it a cross (or X) bracing system instead of the diagonal bracing of the initial tower model.

This alteration attributes a greater stiffness to the altered upper tower segment, increasing its torsional stiffness; however, with the addition of the diagonals, the exposure area to wind actions increases.

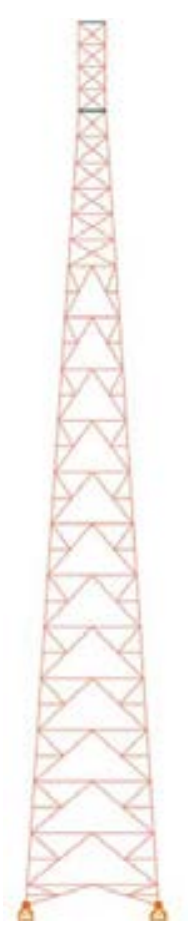

Figure 2 : Tower model A.

\subsection{Tower Model B}

In tower model B (shown in Figure 3 (a) ), the change made consists of varying the spacing between the horizontal diaphragms bracing system. Such change occurred only in the first third part of the structure, up to 37 meters in height, and the spacing chosen between diaphragm levels is 4 meters.

\subsection{Tower Model C}

The tower model C (shown in Figure 3 (b) ) is like tower model B, but now studying the variation of results for a chosen spacing of 5 meters between horizontal diaphragms in the first 37 meters of the tower structure; so, initial tower model has horizontal diaphragm bracing system with 6 meters spacing, while for tower models B and C, such spacing is of 4 meters and 5 meters respectively. 


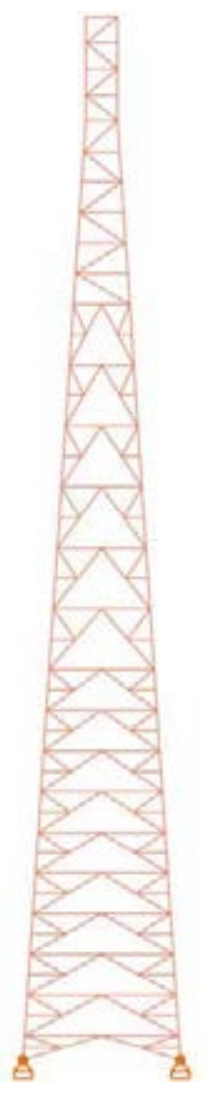

(a)

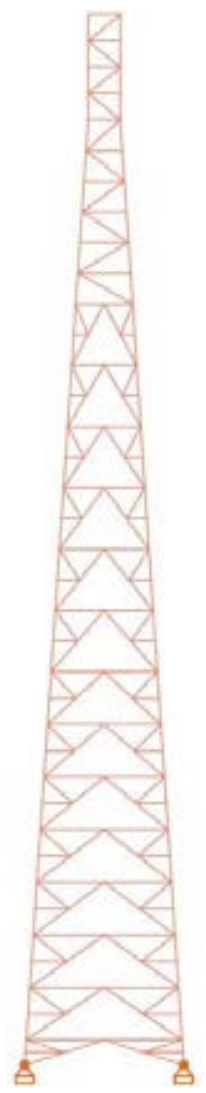

(b)

Figure 3 : (a) Tower model B ; (b) Tower model C.

\subsection{Tower Model D}

The development of the tower model D aims to analyse the structure's behaviour in case the main bracing system in elevation is altered in the first third part of the structure, up to 37 meters in height, from the original " $\mathrm{K}$ " bracing system to a discontinuous bracing system; as shown in Figure 4 (a), this tower model D still presents the continuous horizontal diaphragm bracing system at specific horizontal intersections.

\subsection{Tower Model E}

The tower model E shown in Figure 4 (b), like the tower model D, also aims to study how some alterations of the bracing system influences the operation of the tower, using another variation of discontinuous main bracing system in elevation. In this model tower $\mathrm{E}$, the main " $\mathrm{K}$ " bracing system that exists in elevation in the original tower was replaced entirety up to 72.5 meters in height, by a discontinuous bracing locking system in elevation, but still with continuous horizontal diaphragm bracing system at specific horizontal intersections. 


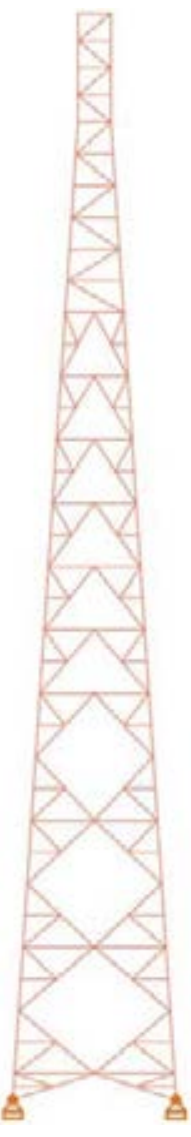

(a)

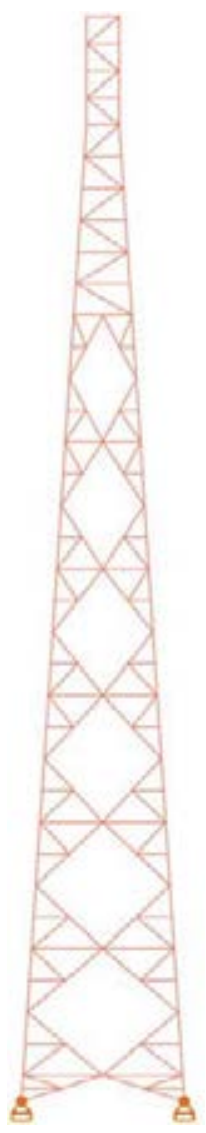

(b)

Figure 4 : (a) Tower model D ; (b) Tower model E.

In Table 2 a brief synthesis is given about the six tower models designed and analysed in this parametric study, but still complying with the metalo-mechanical company experience on lattice towers and its industrial production characteristics. For each design alternative, emphasis is given to the final total weight of the tower (directly related to costs) and to the exposed area to wind in each tower face or incidence plane to wind.

Table 2 : Final weight and exposed areas, for alternative tower models

\begin{tabular}{ccc} 
Tower label & $\begin{array}{c}\text { Total weight of tower } \\
(\mathrm{kgf}) ; 1 \mathrm{kgf} \approx 0.01 \mathrm{kN}\end{array}$ & $\begin{array}{c}\text { Exposed area per face } \\
\left(\mathrm{m}^{2}\right)\end{array}$ \\
\hline Initial tower model & 22354.13 & 95 \\
\hline Tower model A & 23366.31 & 95.5 \\
\hline Tower model B & 29610.04 & 114 \\
\hline Tower model C & 27087.03 & 108 \\
\hline Tower model D & 21928.05 & 93 \\
\hline Tower model E & 21995.66 & 90
\end{tabular}




\section{WIND ACTIONS ON THE TOWERS}

The design guidelines for the regulatory normative of the wind actions on the towers, were the corresponding parts of Eurocodes EC1 and EC3 namely EN 1991-1-4 [4] and 1993-3-1 [5]. Additional comprehensive bibliography used as support were the book chapter of Barros et al. [6] and the article of Calostescu [7]. Also the graduation master's thesis of the second co-author [8] details the remaining expressions and calculations.

\subsection{Wind velocity and dynamic wind pressure}

The tower is located in Zone B mentioned in NP EN1991-1-4/NA [4], to which corresponds a reference wind base velocity of $30 \mathrm{~m} / \mathrm{s}$; the adopted orography coefficient was $\mathrm{c}_{\mathrm{o}}(\mathrm{z})=1$.

For ground category II, parameters $\mathrm{Z}_{0}$ and $\mathrm{Z}_{\mathrm{min}}$ are respectively $\mathrm{z}_{0}=0.05 \mathrm{~m}$ and $\mathrm{Z}_{\mathrm{min}}=2 \mathrm{~m}$.

The turbulence coefficient $K_{I}$ used, was the recommended value of 1. Using specific mass of air $\rho_{\text {air }}=1.25 \mathrm{~kg} / \mathrm{m}^{3}$ - mentioned in clause 4.5 (1) of Eurocode 1 - EN 1991-1-4 [4] - and resorting to the expressions of EC1 [4] and EC3 [5] with respect to characterization of wind actions (by one of the two methodologies in Eurocode annexes), or to the expressions also used in the abovementioned comprehensive bibliography of Barros et al. [6] and Calostescu [7], Table 3 can be systematically obtained. The last two columns in this table (calculation procedure of wind actions - step I) present respectively the dynamic wind pressure (in Pa) and the wind peak velocity (in $\mathrm{m} / \mathrm{s}$ ) at 18 section levels (limiting distinct tower panels), in which the towers were discretized along height at specific elevations $\mathrm{z}$ (in $\mathrm{m}$ ) for improving more accurate determination of distributed wind related quantities.

Table 3 : Calculation procedure - step I

\begin{tabular}{|c|c|c|c|c|c|c|}
\hline Section & $\mathrm{z}(\mathrm{m})$ & $v_{m}(\mathrm{~m} / \mathrm{s})$ & $\boldsymbol{C}_{\boldsymbol{r}}(\mathrm{z})$ & $\boldsymbol{I}_{v}$ & $\boldsymbol{q}_{p}(\mathrm{~Pa})$ & $\begin{array}{l}\mathrm{V}_{\text {peak }} \\
(\mathrm{m} / \mathrm{s})\end{array}$ \\
\hline 1 & 2,37 & 21,994 & 0,733 & 0,259 & 850,818 & 36,895 \\
\hline 2 & 8,21 & 29,076 & 0,969 & 0,196 & 1253,478 & 44,783 \\
\hline 3 & 14,06 & 32,143 & 1,071 & 0,177 & 1447,278 & 48,121 \\
\hline 4 & 19,9 & 34,123 & 1,137 & 0,167 & 1578,664 & 50,258 \\
\hline 5 & 25,756 & 35,593 & 1,186 & 0,1601 & 1679,394 & 51,837 \\
\hline 6 & 31,6 & 36,758 & 1,225 & 0,155 & 1761,169 & 53,084 \\
\hline 7 & 37,44 & 37,725 & 1,258 & 0,15109 & 1830,273 & 54,115 \\
\hline 8 & 43,29 & 38,553 & 1,285 & 0,148 & 1890,361 & 54,996 \\
\hline 9 & 49,14 & 39,275 & 1,309 & 0,145129 & 1943,522 & 55,764 \\
\hline 10 & 55 & 39,917 & 1,331 & 0,143 & 1991,32 & 56,446 \\
\hline 11 & 60,83 & 40,491 & 1,349 & 0,141 & 2034,501 & 57,054 \\
\hline 12 & 66,68 & 41,015 & 1,36 & 0,139 & 2074,216 & 57,609 \\
\hline 13 & 72,53 & 41,494 & 1,383 & 0,137 & 2110,888 & 58,116 \\
\hline 14 & 78,37 & 41,936 & 1,398 & 0,136 & 2144,913 & 58,582 \\
\hline 15 & 84,22 & 42,346 & 1,411 & 0,1346 & 2176,762 & 59,015 \\
\hline 16 & 90,07 & 42,729 & 1,424 & 0,133 & 2206,661 & 59,419 \\
\hline 17 & 95,06 & 43,036 & 1,434 & 0,132 & 2230,8 & 59,743 \\
\hline 18 & 100 & 43,325 & 1,444 & 0,131 & 2253,588 & 60,047 \\
\hline
\end{tabular}




\subsection{Wind force coefficient}

The coefficient of wind force of a lattice metallic tower $c_{f}$, depends on the index of filled parts $\varphi$ defined as the ratio between the solid area per panel and the area of the panel if it was completely filled. In this determination of the coefficient of wind force required for the calculation of wind actions, it is conservatively assumed that the tower is subjected to a super-critic wind flow. For lattice towers of triangular cross section, made of equilateral triangles, the wind causes the maximum drag when its direction is normal to the face, as [9]. So it is going to be considered in these analyses a null or zero angle of attack, that is the wind acts normal to the face of the tower $\left(\theta=0^{\circ}\right)$ and then the wind incidence factor $K_{\theta}=1$.

Table 4 details for the section levels associated with tower panels, the calculation procedure of wind actions - step II: index of filled parts, and corresponding wind force coefficient.

Table 4 : Calculation procedure - step II

\begin{tabular}{cccc} 
Section & $\mathrm{z}(\mathrm{m})$ & $\varphi$ & $\boldsymbol{C}_{\boldsymbol{f}}$ \\
& & & \\
\hline 1 & 2,37 & 0,156 & 1,083 \\
\hline 2 & 8,21 & 0,091 & 1,088 \\
\hline 3 & 14,06 & 0,094 & 1,088 \\
\hline 4 & 19,9 & 0,096 & 1,088 \\
\hline 5 & 25,756 & 0,099 & 1,087 \\
\hline 6 & 31,6 & 0,1 & 1,087 \\
\hline 7 & 37,44 & 0,105 & 1,087 \\
\hline 8 & 43,29 & 0,103 & 1,087 \\
\hline 9 & 49,14 & 0,109 & 1,08 \\
\hline 10 & 55 & 0,110 & 1,086 \\
\hline 11 & 60,83 & 0,117 & 1,086 \\
\hline 12 & 66,68 & 0,128 & 1,085 \\
\hline 13 & 72,53 & 0,133 & 1,085 \\
\hline 14 & 78,37 & 0,144 & 1,084 \\
\hline 15 & 84,22 & 0,143 & 1,084 \\
\hline 16 & 90,07 & 0,165 & 1,084 \\
\hline 17 & 95,06 & 0,153 & 1,083 \\
\hline 18 & 100 & 0,153 & 1,083 \\
\hline & & &
\end{tabular}

\subsection{Structural coefficient}

For the determination of the structural coefficient $c_{s} c_{d}$ the dynamic parameters of the tower were obtained using a finite element method model. The first vibration mode has a frequency very close to unit, so that (in Eurocodes symbology) $\mathrm{n} 1=1$; also, for the logarithmic decrement of structural damping, the value $\delta_{\mathrm{s}}=0.05$ was assumed. The remaining intermediate values necessary for the calculation of the structural coefficients are shown in the following Table 5 through Table 7; for more details, refer to [6] [7] [8].

\begin{tabular}{ccc}
\multicolumn{3}{c}{ Table 5 : Calculation procedure - step III (a) } \\
$\mathrm{L}\left(\boldsymbol{z}_{S}\right)$ & $m_{\varepsilon}(\mathrm{Kg} / \mathrm{m})$ & $\delta_{S}$ \\
\hline 209,181 & 669,5 & 0,05
\end{tabular}


Table 6 : Calculation procedure - step III (b)

\begin{tabular}{|c|c|c|c|c|c|c|c|c|}
\hline Section & $R_{h}$ & $R_{b}$ & $n_{h}$ & $n_{b}$ & $S_{l}$ & $f_{l}$ & $\delta$ & $K_{p}$ \\
\hline 1 & 0,037 & 0,254 & 26,771 & 3,933 & 0,026 & 12,174 & 0,305 & 3,082 \\
\hline 2 & 0,049 & 0,355 & 20,250 & 2,817 & 0,032 & 9,209 & 0,371 & 3,176 \\
\hline 3 & 0,055 & 0,416 & 18,318 & 2,405 & 0,034 & 8,330 & 0,385 & 3,220 \\
\hline 4 & 0,058 & 0,469 & 17,255 & 2,131 & 0,035 & 7,847 & 0,384 & 3,254 \\
\hline 5 & 0,060 & 0,522 & 16,543 & 1,914 & 0,036 & 7,523 & 0,377 & 3,283 \\
\hline 6 & 0,062 & 0,579 & 16,018 & 1,728 & 0,037 & 7,284 & 0,364 & 3,311 \\
\hline 7 & 0,064 & 0,640 & 15,608 & 1,562 & 0,038 & 7,097 & 0,349 & 3,338 \\
\hline 8 & 0,065 & 0,709 & 15,273 & 1,410 & 0,038 & 6,945 & 0,332 & 3,365 \\
\hline 9 & 0,067 & 0,789 & 14,992 & 1,267 & 0,038 & 6,817 & 0,313 & 3,393 \\
\hline 10 & 0,068 & 0,884 & 14,750 & 1,131 & 0,039 & 6,708 & 0,293 & 3,421 \\
\hline 11 & 0,069 & 0,997 & 14,541 & 1,003 & 0,039 & 6,612 & 0,271 & 3,451 \\
\hline 12 & 0,070 & 1,138 & 14,356 & 0,879 & 0,040 & 6,528 & 0,249 & 3,483 \\
\hline 13 & 0,070 & 1,320 & 14,190 & 0,758 & 0,040 & 6,453 & 0,225 & 3,517 \\
\hline 14 & 0,071 & 1,562 & 14,040 & 0,640 & 0,040 & 6,385 & 0,201 & 3,553 \\
\hline 15 & 0,072 & 1,903 & 13,904 & 0,526 & 0,040 & 6,323 & 0,177 & 3,593 \\
\hline 16 & 0,073 & 2,419 & 13,780 & 0,413 & 0,041 & 6,266 & 0,151 & 3,636 \\
\hline 17 & 0,073 & 2,436 & 13,681 & 0,410 & 0,041 & 6,222 & 0,152 & 3,637 \\
\hline 18 & 0,074 & 2,453 & 13,590 & 0,408 & 0,041 & 6,180 & 0,153 & 3,639 \\
\hline
\end{tabular}

Table 7 : Calculation procedure - step III (c)

\begin{tabular}{|c|c|c|c|c|c|}
\hline Section & $\mathrm{z}(\mathrm{m})$ & B (m) & $B^{2}$ & $R^{2}$ & $\mathrm{C}_{\mathrm{S}} \mathrm{C}_{\mathrm{d}}$ \\
\hline 1 & 2,37 & 14,69 & 0,618 & 0,004 & 0,706 \\
\hline 2 & 8,21 & 13,91 & 0,618 & 0,007 & 0,746 \\
\hline 3 & 14,06 & 13,13 & 0,618 & 0,010 & 0,761 \\
\hline 4 & 19,9 & 12,35 & 0,618 & 0,012 & 0,771 \\
\hline 5 & 25,756 & 11,57 & 0,618 & 0,015 & 0,778 \\
\hline 6 & 31,6 & 10,79 & 0,618 & 0,018 & 0,784 \\
\hline 7 & 37,44 & 10,01 & 0,618 & 0,022 & 0,789 \\
\hline 8 & 43,29 & 9,23 & 0,618 & 0,026 & 0,794 \\
\hline 9 & 49,14 & 8,45 & 0,618 & 0,032 & 0,798 \\
\hline 10 & 55 & 7,67 & 0,618 & 0,039 & 0,803 \\
\hline 11 & 60,83 & 6,9 & 0,618 & 0,049 & 0,807 \\
\hline 12 & 66,68 & 6,12 & 0,618 & 0,062 & 0,812 \\
\hline 13 & 72,53 & 5,34 & 0,618 & 0,081 & 0,817 \\
\hline 14 & 78,37 & 4,56 & 0,618 & 0,110 & 0,823 \\
\hline 15 & 84,22 & 3,78 & 0,618 & 0,155 & 0,832 \\
\hline 16 & 90,07 & 3 & 0,618 & 0,233 & 0,849 \\
\hline 17 & 95,06 & 3 & 0,618 & 0,236 & 0,850 \\
\hline 18 & 100 & 3 & 0,618 & 0,239 & 0,851 \\
\hline
\end{tabular}




\subsection{Wind forces}

The wind forces are calculated using the following equation

$$
F_{w}=c_{s} c_{d} c^{*} c^{*} q_{p}\left(z_{\epsilon}\right) A^{\prime} A_{t}
$$

which was shown in detail and with its used explained, in the third chapter of [8].

In Table 8 are presented the quantities used for the calculation of wind force, the wind force value, and the wind force value per node in each panel; again, for more details, refer to [6] [7] [8].

Table 8 : Calculation procedure - step IV

\begin{tabular}{cccccccc} 
Section & $\mathrm{z}(\mathrm{m})$ & $\boldsymbol{C}_{\boldsymbol{S}} \boldsymbol{C}_{\boldsymbol{D}}$ & $\boldsymbol{I}_{\boldsymbol{v}}(\mathrm{z})$ & $\boldsymbol{q}_{\boldsymbol{p}}(\mathrm{Pa})$ & $\begin{array}{c}\boldsymbol{A}_{\boldsymbol{r e f}} \\
\left(\mathrm{m}^{2}\right)\end{array}$ & $\begin{array}{c}\boldsymbol{F}_{\boldsymbol{W}} \\
(\mathrm{kN})\end{array}$ & $\begin{array}{c}\boldsymbol{F}_{\boldsymbol{W}} \text { per } \\
\text { node }(\mathrm{kN})\end{array}$ \\
\hline 1 & 2,37 & 0,706 & 0,259 & 850,818 & 5,466 & 3,56 & 1,19 \\
\hline 2 & 8,21 & 0,746 & 0,196 & 1253,478 & 7,646 & 7,78 & 2,59 \\
\hline 3 & 14,06 & 0,761 & 0,177 & 1447,278 & 7,452 & 8,93 & 2,98 \\
\hline 4 & 19,90 & 0,771 & 0,167 & 1578,664 & 7,116 & 9,42 & 3,14 \\
\hline 5 & 25,76 & 0,778 & 0,160 & 1679,394 & 6,938 & 9,86 & 3,29 \\
\hline 6 & 31,60 & 0,784 & 0,155 & 1761,169 & 6,623 & 9,94 & 3,31 \\
\hline 7 & 37,44 & 0,789 & 0,151 & 1830,273 & 6,401 & 10,05 & 3,35 \\
\hline 8 & 43,29 & 0,794 & 0,148 & 1890,361 & 5,787 & 9,44 & 3,15 \\
\hline 9 & 49,14 & 0,798 & 0,145 & 1943,522 & 5,644 & 9,52 & 3,17 \\
\hline 10 & 55,00 & 0,803 & 0,143 & 1991,320 & 5,212 & 9,05 & 3,02 \\
\hline 11 & 60,83 & 0,807 & 0,141 & 2034,501 & 4,968 & 8,86 & 2,95 \\
\hline 12 & 66,68 & 0,812 & 0,139 & 2074,216 & 4,851 & 8,86 & 2,95 \\
\hline 13 & 72,53 & 0,817 & 0,137 & 2110,888 & 4,445 & 8,31 & 2,77 \\
\hline 15 & 78,37 & 0,823 & 0,136 & 2144,913 & 4,169 & 7,98 & 2,66 \\
\hline 16 & 84,22 & 0,832 & 0,135 & 2176,762 & 3,484 & 6,84 & 2,28 \\
\hline 17 & 90,07 & 0,849 & 0,133 & 2206,661 & 3,266 & 6,62 & 2,21 \\
\hline 18 & 95,06 & 0,850 & 0,132 & 2230,800 & 2,298 & 4,72 & 1,57 \\
\hline 100,00 & 0,851 & 0,132 & 2253,588 & 2,298 & 4,77 & 1,59 \\
\hline
\end{tabular}

\subsection{Wind forces on equipment auxiliary structures}

For the calculation of the forces acting on equipment auxiliary structures, an equipment exposed area of $30 \mathrm{~m}^{2}$ was allowed in the last 10 meters from the top of the tower. Account was also taken on the existence of an access staircase throughout the height of the tower, as well as $0.30 \mathrm{~m}$ of cablings width across the height.

Table 9 shows the values of wind forces in auxiliary structures, and their section level of actuation. 
Table 9 : Wind forces on equipment auxiliary structures

\begin{tabular}{ccc} 
Section & $\boldsymbol{F}_{\boldsymbol{W}}(\mathrm{kN})$ & $\begin{array}{c}\boldsymbol{F}_{w} \text { per } \\
\text { node }(\mathrm{kN})\end{array}$ \\
\hline 7 & 1,35 & 0,45 \\
\hline 9 & 1,20 & 0,40 \\
\hline 16 & 11,8 & 3,83 \\
\hline 17 & 11,64 & 3,88 \\
\hline 18 & 11,72 & 3,91
\end{tabular}

\subsection{Combinations of actions}

The combinations of actions used in this parametric study for the ultimate limit state (ULS) are shown in Tables 10-11-12. Tables 10 and 11, detail the conditioning combinations for the determination of generalized forces; and Table 12 details the conditioning combination for the determination of displacements.

Table 13 details the conditioning combination of actions used in this parametric study for the determination of displacements under the serviceability limit state (SLS).

For a better understanding of the combinations detailed, the nomenclature used and its meaning is the following: PP refers to self-weight; Wind_Y+ refers to wind acting along the direction $\mathrm{Y}+$; Wind $\mathrm{Y}$ - refers to wind acting along the direction $\mathrm{Y}-$; Wind_X refers to wind acting along the direction X ; PLAT SW refers to platform self-weight; PLAT LL refers to platform live load.

Table 10 : Combination of actions for ULS - generalized forces ( $1^{\text {st }}$ combination)

\begin{tabular}{cc} 
Factor & Action \\
\hline 1.2 & PP \\
\hline 1.2 & PLAT SW \\
\hline 1.12 & PLAT LL \\
\hline 1.6 & Wind_Y+
\end{tabular}

Table 11 : Combination of actions for ULS - generalized forces ( $2^{\text {nd }}$ combination)

\begin{tabular}{cc} 
Factor & Action \\
\hline 1.2 & PP \\
\hline 1.2 & PLAT SW \\
\hline 1.12 & PLAT LL \\
\hline 1.6 & Wind_X
\end{tabular}


Table 12 : Combination of actions for ULS - displacements

\begin{tabular}{cc} 
Factor & Action \\
\hline 1.2 & PP \\
\hline 1.2 & PLAT SW \\
\hline 1.12 & PLAT LL \\
\hline 1.6 & Wind_Y-
\end{tabular}

Table 13 : Combination of actions for SLS - displacements

\begin{tabular}{cc} 
Factor & Action \\
\hline 1.0 & PP \\
\hline 1.0 & PLAT SW \\
\hline 0.64 & Wind_Y-
\end{tabular}

\section{ANALYSIS OF RESULTS}

Table 14 shows the values of the generalized reactions at the base of the towers, obtained at each tower model analysed in accordance with the ULS combinations of Tables 10 and 11. These generalized reactions are respectively the force reactions in the horizontal base plane $\left(F_{x}\right.$ and $\left.F_{y}\right)$ and the vertical force reaction $F_{z}$; as well as the two moment reactions $\mathrm{M}_{\mathrm{x}}$ and $\mathrm{M}_{\mathrm{y}}$ at the base of the towers.

Table 14 : Values of Reactions at the base of the towers for ULS

\begin{tabular}{|c|c|c|c|c|c|c|c|c|}
\hline \multirow[b]{2}{*}{ Tower label } & \multicolumn{2}{|c|}{$\mathrm{Fx}(\mathrm{kN})$} & \multicolumn{2}{|c|}{ Fy $(k N)$} & \multicolumn{2}{|c|}{$\mathrm{Fz}(\mathrm{kN})$} & \multirow{2}{*}{$\begin{array}{c}\mathrm{Mx} \\
(\mathrm{kNm})\end{array}$} & \multirow{2}{*}{$\begin{array}{c}\text { My } \\
(\mathrm{kNm})\end{array}$} \\
\hline & Max & Mín & Max & Mín & Max & Mín & & \\
\hline $\begin{array}{l}\text { Initial tower } \\
\text { model }\end{array}$ & 72 & -134 & 142 & -170 & 1330 & -1148 & 17294 & 15855 \\
\hline Tower model A & 74 & -139 & 148 & -176 & 1401 & -1212 & 18213 & 16774 \\
\hline Tower model B & 77 & -142 & 142 & -178 & 1378 & -1144 & 17914 & 16041 \\
\hline Tower model C & 77 & -140 & 149 & -181 & 1381 & -1164 & 17953 & 16178 \\
\hline Tower model D & 74 & -134 & 144 & -171 & 1321 & -1141 & 17173 & 15817 \\
\hline Tower model E & 71 & -131 & 140 & -167 & 1321 & -1141 & 17173 & 15772 \\
\hline
\end{tabular}

From the analysis of the results of this parametric study, each tower identity or parameter of change can be easily distinguished. Tower model A has the highest bending moments $\left(\mathrm{M}_{\mathrm{x}}\right.$ and $\mathrm{M}_{\mathrm{y}}$ ) at the base due to the increase in the wind force because of the increase in the exposure area of this model has been made at the top of the structure, greatly influencing the value of the moments at the base.

In the tower models $\mathrm{B}$ and $\mathrm{C}$, the two bending moments at the base are superior to the moments at the base of the initial tower model: for reasons already explained above, and also because the compromise between increased wind action and increased stiffness (due to the resizing) did not prove to be beneficial at this point. 
In the tower models $\mathrm{D}$ and $\mathrm{E}$, the two bending moments at the base are slightly lower than the moments at the base of the initial tower model: because the action of the wind on these tower models is slightly less than the action of the wind on the original tower, thus generating smaller moments.

Regarding the values of the generalized displacements (lateral displacements and torsional rotation through vertical global axis) in accordance with the SLS combination of Table 13, their results are presented in Table 15 for the top as well as for sections at two-thirds and onethird of the tower height $(\mathrm{H})$.

Table 15 : Values of lateral displacements and rotations, for the SLS

\begin{tabular}{|c|c|c|c|c|c|c|}
\hline \multirow{2}{*}{ Tower model } & \multicolumn{3}{|c|}{ Lateral displacement $(\mathrm{cm})$} & \multicolumn{3}{|c|}{ Rotation along vertical axis $\left({ }^{\circ}\right)$} \\
\hline & Top & $2 / 3 \mathrm{H}$ & $1 / 3 \mathrm{H}$ & Top & $2 / 3 \mathrm{H}$ & $1 / 3 \mathrm{H}$ \\
\hline Initial tower & 31,1 & 14,7 & 3,9 & 0,526 & 0,321 & 0,134 \\
\hline Tower A & 32,9 & 15,6 & 4,1 & 0,497 & 0,351 & 0,139 \\
\hline Tower B & 32 & 15,2 & 4,1 & 0,532 & 0,327 & 0,123 \\
\hline Tower C & 32 & 15,1 & 4 & 0,531 & 0,330 & 0,128 \\
\hline Tower D & 31,2 & 14,8 & 4 & 0,523 & 0,321 & 0,131 \\
\hline Tower E & 32,1 & 15,5 & 4 & 0,529 & 0,325 & 0,160 \\
\hline
\end{tabular}

In general, it is observed that the difference in lateral displacements is not significant: of the order of $1 \mathrm{~cm}$ in the top section for models A-B-C-E, and $1 \mathrm{~mm}$ for model D; much smaller differences at the other tower sections. With regards to rotation along vertical axis, all the tower models have rotation values quite identical, except the top rotation of tower model A; in fact, for this tower model A the maximum rotation is $5 \%$ to $7 \%$ lower than maximum rotation of the other tower models. This could be expected because the increase of the stiffness of the top third part of the tower structure (above $72.5 \mathrm{~m}$ ) by adding an additional diagonal member, converting the initial diagonal bracing into a cross X-bracing, leads to an expected reduction of torsional rotations at the top tower levels.

\section{CONCLUSIONS}

All the proposed tower models were resized or redesigned, leading to changes in the type of circular profile used in various sections and in the total number of elements used. These changes, besides leading to different structural responses when the towers were subject to wind action (as previously explained and analysed), also lead to different costs of the models proposed tower structures. Table 16 shows an estimate of the total weight of each tower and an estimate of the price of each tower, considering a market value for the steel price of around 2.5 euros per kilogram-force of weight.

In view of the foregoing considerations -- both in terms of the generalized reaction values and generalized displacements, and in terms of estimated total cost associated with the studied solutions in this parametric study -- it is thought that, in addition to the original solution associated with the initial tower model structure, the most indicated alternatives may be the tower models D and E. 
Table 16 : Cost estimate of the tower models

\begin{tabular}{ccc} 
Tower model & $\begin{array}{c}\text { Total weight of tower } \\
(\mathrm{kgf}) ; 1 \mathrm{kgf} \approx 0.01 \mathrm{kN}\end{array}$ & $\begin{array}{c}\text { Cost estimate of tower } \\
(\text { Euro })\end{array}$ \\
\hline Initial tower & 22354.13 & 55885.33 \\
\hline Tower A & 23366.31 & 58415.79 \\
\hline Tower B & 29610.04 & 74025.09 \\
\hline Tower C & 27087.03 & 67717.57 \\
\hline Tower D & 21928.05 & 54820.13 \\
\hline Tower E & 21995.66 & 54989.14
\end{tabular}

\section{ACKNOWLEDGEMENTS}

This work was financially supported by: Base Funding - UIDB/04708/2020 of the CONSTRUCT - Instituto de I\&D em Estruturas e Construções - funded by national funds through the FCT/MCTES (PIDDAC).

\section{REFERENCES}

[1] S. Sreevidya and N. Subramanian -- "Aesthetic appraisal of antenna towers"; J. Archit. Eng., vol. 9, no. 3, pp. 102-108, 2003; doi: 10.1061/(ASCE)1076-0431(2003)9:3(102).

[2] B. W. Smith -- Communication Structures; Thomas Telford Ltd, London, 2007.

[3] D. Vieira, and R. Carneiro-Barros -- "Tubular Steel Lattice Telecommunication Towers, Subjected to Wind Loading and Vortex Shedding"; in COMPDYN 2017 Proceedings of the 6th International Conference on Computational Methods in Structural Dynamics and Earthquake Engineering, 2:3154-62. National Technical University of Athens (NTUA); 2017. doi: 10.7712/120117.5635.20402.

[4] CEN 2010 -- Eurocódigo 1 - Acções em estruturas - Parte 1-4: Acções gerais - Acções do vento; NP EN 1991-1- 4, Norma Europeia, Portugal: IPQ; 2010.

[5] CEN 2006 -- Eurocode 3: Design of Steel Structures - Part 3-1: Towers, Masts and Chimneys; Brussels; 2005.

[6] R.C. Barros, N. Ferreira and R. Delgado -- "Effects of Wind in Tall Buildings: a comparison for a real case and its vibration control using a Tuned Mass Damper"; chapter of the book Tall Buildings: Design Advances for Construction (edited by J.W. Bull), Saxe-Coburg Publications - UK, ISBN: 978-1-874672-25-8, 2014.

[7] I. Çalostescu -- "Wind Loads on Structures: Software Application II. Towers"; Buletinul Institutului Politehnic Din IASI, Tomul LIX (LXIII), Fasc. 5, pp. 49-61, Sectia: Constructii Arhitectura; 2013.

[8] L.M.R.G. Barros -- "Estudo Paramétrico de Torres Treliçadas (Comparação de Esquemas de Contraventamento)"; M.Sc. thesis in structural engineering supervised by Prof. Rui Carneiro Barros, FEUP, Porto-Portugal, October 2020 (in Portuguese).

[9] P. Sachs -- Wind Forces in Engineering, 2nd Ed.; Pergamon Press, Oxford, New York; 1978.s, Wind Forces in Engineering. 1978. 